\title{
Das Bild der Polen als Heterokonstruktion in Zwischenkriegsromanen der Region Ostravsko: Tschechisch-deutsche imagologische Untersuchung ${ }^{1}$
}

\section{Einleitung}

Ostrau und das Umland der Stadt stellen vor allem aufgrund der Grenznähe ein interessantes Feld für die imagologische Forschung dar, ebenso jedoch aufgrund der industriellen Entwicklung und weiterer historischer Ereignisse, auf deren Grundlage es hier zur Vermengung zahlreicher Ethnien kam, wie zum Beispiel der polnischen, deutschen, tschechischen, jüdischen, aber ebenso derjenigen der Roma. Konkret rücken bei der vorliegenden vergleichenden Studie die Heterobilder der Polen in der Romanprosa in der größeren Region Ostravsko zwischen den beiden Weltkriegen ins Zentrum des Interesses. Es werden die Romane untersucht, die während dieser Zeitperiode geschrieben, modifiziert oder herausgegeben wurden. ${ }^{3}$

1 Diese Studie wurde durch das SGS-Projekt (SGSO2/FF/2020 Hranice a kulturní transfery. Př́spěvky k literární komparatisticel SGSO2/FF/2020 Grenzen und Kulturtransfers. Beiträge zur literarischen Komparatistik) an der Universität Ostrau unterstützt.

2 Mit dem Begriff ist das Gebiet der Periodenbezeichnung Moravskoostravská župa gemeint (auf der Grundlage des sogenannten župního zákona/Gaugesetzes 1920). Das Gebiet wurde 1927 in Moravskoslezská země umbenannt und Těšínská župa wurde ebenfalls daran angegliedert. Es geht um das Gebiet von Nord- und Nordostmähren und einen Teil des tschechischen Schlesiens. Weiterführend in Malír, Marek 2005: 400-402.

3 Romane von Sokol-Tůma wurden schon anfangs des 20. Jahrhunderts geschrieben, trotzdem sind sie erst in den 1920er Jahren herausgegeben und reflektiert worden, bis 
Um den Rahmen der Studie nicht zu sprengen, wurde das verwendete Material durch einige Kriterien eingegrenzt. Zunächst ist dies die regionale Verankerung; es wird versucht, eine Entwicklungslinie des künstlerischen Konzepts des Bildes im Rahmen der untersuchten Region herauszuarbeiten, weshalb Autoren ausgewählt wurden, die direkt mit der Region im Zusammenhang stehen und eventuell ihr Werk in engem Kontakt mit ihr verfasst haben.

Neben der Zeitspanne wird der Forschungsgegenstand ebenso hinsichtlich des Genres eingegrenzt. Der Fokus liegt auf Romanwerken, die als primäre Themen sozialkritische Gedanken aufnehmen und sich eventuell mit der Frage nach Ethnie oder Rassenzugehörigkeit befassen. Die Präferenz liegt hierbei auf den Genres des Bauern-, Sozial-, Gesellschafts- oder Grenzlandromans.

Die Studie ist ein Teil einer umfangreicheren Forschung, die sich mit der Konstruktion von Auto- und Hetero-Bildern in den Romanen der oben erwähnten Zeitspanne und Region befasst. Die Forschung beschäftigt sich eingehend mit den Werken tschechischer Autoren (František Sokol-Tůma, Vojtěch Martínek, Ludmila Hořká, Ladislav Třenecký, A.C. Nor, Karel Dvořáček, Jarmila Glazarová) und vergleicht deren Konstruktion der Bilder mit dem Bildaufbau in Werken deutscher Schriftsteller der gleichen Epoche (Ernst Wolfgang Freissler, Maria Stona, Gottfried Rothacker, August Scholtis).

Die hier vorgestellte Studie stellt das Bild der Polen und seine Entwicklung in den Mittelpunkt des Interesses, die anderen Themen wie z.B. die Rolle des Genres, Konstruktion Auto- oder Hetero-bilder der anderen Ethnien wurden im Rahmen vorangehender Studien bearbeitet. Aus dem ganzen Spektrum werden nur die Autoren vorgestellt, die die Entwicklung des Polenbildes charakterisieren. Zunächst wird versucht, die komplexeste Bildkonstruktion im Werk von Sokol-Tůma und August Scholtis zu analysieren. Bei den anderen Autoren, die kein komplexes Bild konstruieren, werden zumindest einzelne Fragmente beschrieben.

\section{Theorie und Methode der Imagologie}

Aktuell ist die Imagologie eine breite und interdisziplinäre Disziplin, deren Ziel es ist, literarische Bilder und ihre Konstruktionen im literarischen Text verständlich zu machen. Lenka Adámková betont, dass es erforderlich ist,

zu diesem Zeitpunkt überarbeitete Sokol-Tůma seine Texte mehrmals. Der Roman František chce být spravedlivý von Karel Dvořáček wurde am Ende der 193oer Jahre vollendet, aber wegen der Zensur erst in den 1960er Jahren herausgegeben. Es werden also die Texte jener Zeitperiode analysiert, die von der kulturellen und sozialen Atmosphäre der Tschechoslowakei in der Zwischenkriegszeit beeinflusst wurden. 
auch die Rahmenbedingungen zu untersuchen, welche die Bildkonstruktion beeinflussen konnten:

Die personellen und institutionellen Elemente, zu denen auch politische und kulturpolitische Rahmenbedingungen zählen, die dem System nicht angehören, es aber in seiner Entstehung, Wahrnehmbarkeit und Wahrnehmung beeinflussen, bezeichnen wir als seine transgredienten Grundlagen. Wenn sich Imagologie als interdisziplinäre Literaturwissenschaft versteht, muss sie ihren Blickwindel vom literarischen Text auf diese transgredienten Grundlagen imagotyper Systeme ausweiten (Adámková 2011: 12).

Im Mittelpunkt der Disziplin stehen selbstverständlich die Begriffe „Bild“ und „Image“, welche in imagologischen Studien sehr oft synonymisch ${ }^{4}$ benutzt werden. Aus sprachlichen Gründen wird in dieser Studie, mit Hinblick auf die untersuchten Autoren sowie die Zeit, der Begriff „Bild“ bevorzugt, wodurch an eine Begrifflichkeitslinie der Imagologie angeknüpft wird, die von Autorinnen und Autoren wie Hugo Dyserinck, ${ }^{5}$ Michaela Voltrová, Elke Mehnert, Lenka Adámková, ${ }^{6}$ Gabrielle Schubert ${ }^{7}$ u. a. präsentiert wird.

Im Einklang mit der sogenannten Chemnitzer literarischen Schule wird „Bild“ als ein System ${ }^{8}$ verstanden. In diesem Zusammenhang benutzt Mehnert den Terminus „das imagotype System“:

[Das imagotype System ist] Gesamtheit der imagotypen Elemente in ihrer jeweiligen Struktur. Das imagotype System existiert auf verschiedenen Textebenen (Der Erzählinstanz, des Figurenensembles, der

4 „Der Begriff Image (image) ist abgeleitet vom lateinischen Wort imago, dass in der deutschen Sprache Bild bedeutet. So ist es nicht überraschend, dass (wie auf den nächsten Seiten demonstriert wird) die Termini Image und Bild in der komparatistischen Imagologie parallel angewandt werden und fast identische Phänomene bezeichnen.“ (Voltrová 2015: 37). Die Phänomene sind „fast" identisch, der konkrete Unterschied wird in dieser Studie wie folgend verstanden. „Image“ ist im Deutschen eher der theoretische und allgemeine Begriff, bezogen auf die imaginäre Vorstellungswelt; „Bild“ ist die konkrete, bildhafte Vorstellungswelt.

5 Siehe weiterführend Dyserinck 2002, uns 2015.

6 Siehe weiterführend Adámková 2011.

7 Siehe weiterführend Schubert 2003.

8 „[System wird verstanden als] Mengen von Elementen, zwischen denen Wechselbeziehungen bestehen. Alles, was nicht Element des Systems ist, was nicht dazu gehört, ist dessen Umwelt.“ (Becker in Votrová 2015: 60). 
Motivik, Symbolik ...) [...] Imagotype Elemente können ihrerseits als imagotype Subsysteme mit eigener Binnenstruktur betrachtet werden (Mehnert in Voltrová 2015: 58).

Das imagotype System kann ikonisch wie folgt dargestellt werden:

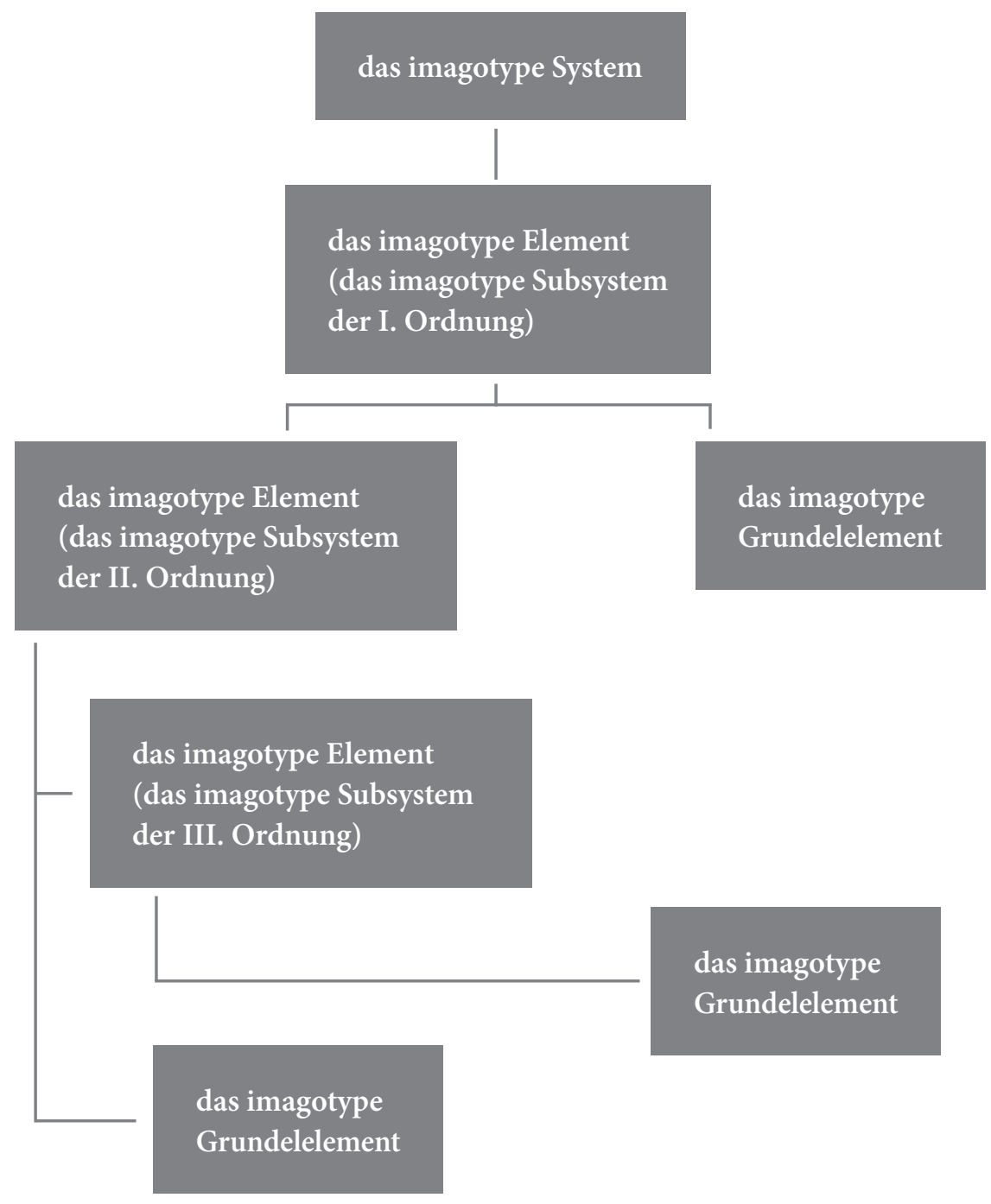

Ab. 1: Systematische Darstellung des imagotypen Systems (Voltrová 2015: 62) 
Für die moderne Imagologie mit Entwicklungen zum Beispiel in den Niederlanden ist hier einer der wesentlichen Vertreter Joep Leerssen, der in seiner Studie Imagology: On using ethnicity to make sense of the world (2016) betont, dass neben den allgemeinen Imagotypen noch sogenannte Ethnotypen existieren, also Darstellungen eines ethnischen Charakters, der eine Ethnie von einer anderen trennt. Die Ethnotypen selbst müssen laut Leerssen (Leerssen 2016: 17-18) in Abhängigkeit von ihrer Zeit und ihrem Kontext interpretiert werden.

Der Ethnotyp wird innerhalb des Werks aus den Positionen der sogenannten „Auto-“ und „Heteroperspektive“ geformt. Die Perspektiven bestimmen den Ursprung des Blicks auf die eigene wie die fremde Ethnie; darauf beruhen „Autobilder“ oder „Heterobilder“. Es handelt sich um Sichtweisen auf eine Realität, die mit der Wirklichkeit selbst keinesfalls übereinstimmen müssen. Während Auto- folglich auf die Sichtweise des Einzelnen hinweist, der innerhalb der eigenen sozialen Gruppe/Erscheinung existiert, bestimmt das Präfix Hetero- immer den Blick von außen auf die jeweilige andere Gruppe. ${ }^{9}$

Elke Mehnert (Vertreterin der sogenannten Chemnitzer imagologischen Schule) nennt diesen Kontext der Entstehung von Bildern, der nicht direkter Bestandteil des untersuchten Bildes ist, sondern dessen „Umfeld“, als die „transgrediente Grundlage“ (Mehnert 1997: 44). Der Begriff umfasst die biologischen, sozialen, historischen und politischen Faktoren, ${ }^{10}$ die den $\mathrm{Au}$ tor während der Entstehung eines künstlerischen Textes beeinflusst haben. Mehnert betont, dass diese Elemente, wenn die Imagologie als interdisziplinäre Literaturwissenschaft verstanden werden soll, in imagologische Studien einbezogen werden müssen. ${ }^{11}$

Es wird immer versucht, die Elemente des polnischen Bildes komplex und umfassend $\mathrm{zu}$ interpretieren (in der Verbindung zum ganzen Text), um die „intentio operis“ und damit auch ,intentio auctoris“ ersichtlich zu machen. Laut Jan Mukařovský ist die Absicht die Stärke, die: „die einzelnen Teile und Komponenten des Werks verbindet, und damit dem Text Sinn gibt“. ${ }^{12}$ Besonders wichtig ist die Formation des polnischen Bildes im Rahmen des vereinheitlichen Aufbaus des Werkes, die durch eine Analyse der Handlung, des Themas, anhand der Häufigkeit des Auftretens einzelner Elemente eröffnet wird.

9 Siehe weiterführend Voltrová 2015: 28-29.

10 Siehe weiterführend Mehnert 2016

11 Siehe weiterführend Mehnert 1997: 44.

12 Mukařovský, verfügbar [online], [zit. 2019-03-16], unter: https://tinyurl.com/y24c7oup. 


\section{Textanalyse}

\subsection{František Sokol-Tůma}

Aus chronologischer Perspektive ist es erforderlich, die Textanalyse mit dem ältesten Autor zu beginnen. Sokol-Tưma ${ }^{13}$ wurde bereits 1855 geboren, weshalb er den Ausgangspunkt für die Literatur der Zwischenkriegszeit in der Region Ostravsko bildet. Vojtěch Martínek betont, dass die Texte Sokol-Tưmas in ihrer Zeit nicht nur ästhetische und künstlerische Interessen darstellten, sondern von den Lesern auch als Beschreibung der Gegenwart verstanden wurden. Tůma hebt die Verbindung seiner Texte mit der realen Welt in den Fußnoten selbst hervor. Jene Anwesenheit der Fußnoten, die sich sehr oft in seinen Romanen befinden, ist für ihn sehr charakteristisch. Martinek erwähnt konkret:

[texty od Sokola-Tůmy vykazují] poučující a uvědomovací poslání. Nebot' František Sokol-Tůma nikdy nechtěl, aby jeho děje byly pouze výmyslem a projevem tvưrčí fantazie. Zdůrazňoval vždy, že chce podati ve svém díle odlesk skutečnosti. ${ }^{14}$ (Martínek 1926: 15).

Černé království15 stellt einen Zyklus relativ umfangreicher, engagierter Romane dar. Die Entwürfe der ersten zwei Teile entstanden laut Martínek bereits zwischen 1900 und 1904 ${ }^{16}$ (Martínek 1926: 42-43), damit würden die Texte nicht in die Zeitspanne dieser Studie fallen, aber laut Martínek arbeitete

13 (1855 Benešov - 1925 in Mährisch Ostrau). Schriftsteller, Schauspieler, Rezitator, Journalist. Tätigkeit in Ostrau, Valašské Meziř́číi. Arbeit bei den Zeitschriften Ostravský obzor (1897-1901), Ostravan (1901-1912), Horník (1910-1923). Seine Werke konzentrieren sich auf die Walachei und die Region Ostravsko, die Figuren stammen häufig aus dem Arbeiter- oder Bergbaumilieu. Die Texte sind stark engagiert, antideutsch. Sein Werk ist von Schemenhaftigkeit durchzogen, bezüglich der Imagologie sind nur einige grundlegende Muster zu erkennen, die in späteren Werken weiterhin zum Tragen kommen.

14 „[Die Texte Sokol-Tůmas weisen] eine belehrende und bewusstmachende Mission auf. Denn František Sokol-Tůma wollte nie, dass seine Werke nur Fiktion sind und Ausdruck schöpferischer Fantasie. Er betonte stets, dass er seinem Werk einen Abglanz der Wirklichkeit beifügen möchte." (Soweit nicht anders vermerkt, stammen alle Übersetzungen vom Verfasser)

15 Die Trilogie besteht aus folgenden Romanen: V záři milionů, Na šachtě, Pan závodní.

16 Hier muss darauf hingewiesen werden, dass der erste Teil des Romans, unter dem Titel E'Geschäftsmann, veröffentlicht in Zeitschriften, nicht die Ankunft Chaims in Ostrau widerspiegelte. Die Einführungsteile des Romans über das Aufwachsen Chaims veröffentlicht der Autor erst in der chronologischen Buchüberarbeitung. Angaben entnommen aus (Borovička, Strobach 2017). Die Zeitschriftenausgaben der Vorkriegszeit sind 
Sokol-Tůma jedoch weiterhin an den Texten. Konkret wurde der erste Teil neu überarbeitet und bis 1914 erweitert, dann wurde er dem Verleger Alois Zelinek angeboten und erst 1922 veröffentlicht. Die Romane beeinflussen also das literarische Spektrum maßgeblich vor allem in den 1920er Jahren, wo sie ebenfalls reflektiert werden.

Als Hauptquelle imagologischer Muster wurde der Roman $V$ zári miliónu ausgewählt, der ursprünglich den Titel $E^{\prime} G e s c h a ̈ f t s m a n n$ tragen sollte. Vzári miliónů kann auch als Text verstanden werden, der das komplexeste Spektrum der Heterobilder darstellt. Es können Bilder von Juden, Deutschen und ebenfalls das Autobild des „slawischen Elements“ ${ }^{{ }^{17} 7}$ gefunden werden.

Ein charakteristischer Zug des Romans von Sokol-Tưma ist die Konstruktion des Bildes der Slawen. Bei keinem der Autoren, die nach ihm folgen, ist die Bemühung um die Darstellung eines so einheitlichen slawischen Bildes zu finden, stattdessen zerfällt das komplexe Slawentum in Teilbilder. Das von Sokol-Tůma untersuchte Element heißt das „slawische Element“ ${ }^{18}$ das sich vor allem aus den Tschechen (Mährern) und Polen zusammensetzt. Sokol-Tůma ist unter den tschechischen Autoren hinsichtlich der Darstellung des polnischen Bildes sehr spezifisch, da eben hierbei in den folgenden Generationen auf tschechischer Seite ein deutlich vermindertes Interesse verzeichnet werden kann. ${ }^{19}$

Bei näherer Betrachtung des Bildes des slawischen Elements stellen wir fest, dass die Struktur eine bedeutende Rolle bei der engagierten Gesamtkonstruktion des Werks spielt. D.h. es geht hier um den Versuch, slawische Nationen (Tschechen und Polen) zu verbinden und Germanisierung sowohl als auch jede Formen des Radikalismus abzulehnen, die die Position der tschechischen Nation in ihrem eigenen Land destabilisieren können.

Hinsichtlich das ganze Bild des slawischen Elements stimmt die Darstellung von Tschechen, und Polen (aus Galizien bzw. Schlesien) in den Romanen von Sokol-Tůma in großem Maße damit überein, wie der gegebene Zustand durch die moderne Geschichtsschreibung geschildert wird, insbesondere in Bezug auf die Migrationsfrage.

nicht Gegenstand dieser Studie, das Gesamtwerk wird erst thematisiert, wenn es auf das komplexe Bild verweist.

17 Vgl. mit der Tendenz Sokol-Tůmas zu der Verbindung von Slawen zu einem einzigen „slawischen Element“, genauer erörtert weiter unten.

18 Im Orig. „Slovanský živel“.

19 Polen wird vor allen Dingen auch auf deutscher Seite thematisiert, konkret in der Überlieferung von z. B. Scholtis, allerdings nimmt auch hier die Konstruktion des polnischen Bildes keine primäre Rolle ein. 
Der Erzähler verbindet den ersten Migrationsschub mit Galizien, was auch ein realer Fakt war. Im Jahre 1900 hatte das sich rasch entwickelnde Mährisch Ostrau die folgenden Bevölkerungsanteile in Bezug auf die Migrationsherkunft: 41\% Morawaner, 23,4\% Schlesier, 4,4\% Tschechen, 26,6\% Immigranten aus Galizien (Gawrecká 2014: 99). Über die Emigrationsprozesse aus dem galizischen Gebiet gibt es relativ umfangreiche Literatur, ${ }^{20}$ es zogen im 19. Jahrhundert von dort aus etwa 8 Millionen Menschen nach Europa und Amerika (Gawrecká 2014: 101), zu den Hauptursachen dieses Prozesses werden ein unzureichendes $\mathrm{Maß}$ an fruchtbarem Boden gezählt, wirtschaftliche sowie soziale Rückständigkeit, ${ }^{21}$ aggressive Auseinandersetzungen zwischen polnischen und russischen Galiziern, der polnische Aufstand in Galizien 1846 u. ä.

Hinsichtlich der imagologischen Interpretation der Beziehung zwischen dem Bild der Polen und Tschechen ist vor allem die Darstellung der „slawischen Wechselseitigkeit“ bedeutend, die faktisch eine manipulative Komponente im Aufbau des Werks darstellt, da die Bedrohung des Slawentums durch die Deutschen für alle Slawen gültig ist. Diese müssten sich laut Erzähler verbünden, aus dem Schlaf erwachen und den sie umgebenden radikalen Tendenzen die Stirn bieten, wobei hier die größte Gefahr das Deutschtum und dessen Instrument, die Germanisierung, darstellen. Die Herkunft der Slawen ist hier also direkt mit dem universalen ${ }^{22}$ Unrecht verknüpft. Das slawische Volk wird laut Erzähler herabgesetzt, bestohlen und seine Erniedrigung gerate zu oft in Vergessenheit:

Největší kletbou lidu slovanského a původem všeho neštěstí je, že lehko zapomíná a odpouští. Je to snad křestanské, ale je to národním neštěstím, poněvadž v tomto odpouštění a zapomínání je hrob naší politické, národní i hospodářské samostatnosti. V tom, že lížeme slinu, jíž jsme byli poplváni a neumíme se rozehnat proti nepříteli tu či jinde, jenž nás bije tím či oním způsobem, kotví neúspěch všech národů slovanských, neúspěch nejen politický, ale i národní a národohospodářský... Jen se rozehnat k obraně jako ten polský ,chlop a šlo

20 Z.B. Pilch Trendy migracji zarobkowej ludności Galicji w XIX $i$ XX w. (do 1918 r.) oder Bobińska Mechanizmy polskich migracji zarobkowych u. a.

21 Die Wahrnehmung der Region Ostravsko durch die Polen wird auch von Michał Przeperski in seiner Monographie Nieznośny ciężar braterstwa festgehalten. Aus dem Zitat der Zeitschrift Swiat Slowianski aus dem Jahr 1910 wird ersichtlich, dass die zeitgenössische Presse sogar die sog. Saisonemigration in die Region Ostravsko-Karwin für die Arbeit in der Schwerindustrie unterstützt hat (Przeperski 2016: 53).

22 Das Unrecht ist „universal“, denn es ist für alle Slawen gültig. Alle sind bedroht. 
by to. Či nemá už lid slovanský ani odvahy, ani síly... “23 (Sokol-Tůma 1935, Teil 1.-2.: 97).

Sokol-Tůma fordert also zum aktiven Kampf gegen den Unterdrücker auf, den Deutsche und radikalisierte Juden (als manipuliertes Instrument der Deutschen) darstellen. Es wird vermutet, dass genau in dem oben angeführten Auszug die Verbindung aller genannten Subsysteme deutlich erkennbar ist, wodurch die gesamte Intention des Werks gekennzeichnet ist.

Interessant ist auch das Subsystem, das die gemeinsamen menschlichen Züge darstellt. Die Tschechen verbindet Brüderlichkeit mit den Polen, wie in dem nachfolgenden Auszug erkennbar wird, wo sich der Erzähler als Tscheche stilisiert und den Polen als seinen Bruder bezeichnet:

Že nebývá ,inteligence‘ tato, ucpávající přítomností svou u nás vzniklé mezery, vždycky nejvybranější, není vinou bratří Poláků, jichž také nikterak neobviňuji. ${ }^{24}$ (Sokol-Tůma 1935, Teil 1.-2.: 135).

Hier sind allerdings evidente Unterschiede zwischen Tschechen und Polen zu erkennen, z.B. haben die Tschechen eine deutlich bessere Ausbildung genossen und verfügen über bessere Sprachkenntnisse (Sokol-Tůma 1935, Teil 1.-2.: 182). Dies stimmt mit den Informationen über die damalige Situation in der Region Ostravsko überein. Die aus Galizien stammenden Bewohner waren größtenteils Analphabeten. ${ }^{25}$ Es ist zu betonen, dass das Bild der Polen im Werk zum großen Teil gerade durch die Migrations- bzw. Galizienkomponente der Bevölkerung geformt wird. Es wird eine der grundlegenden Säulen für

23 „Der größte Fluch des slawischen Volks und der Ursprung allen Unglücks ist es, dass leicht vergessen und verziehen wird. Es ist wohl christlich, aber ein nationales Unglück, da in dieser Vergebung und diesem Vergessen das Grab unserer politischen, nationalen und wirtschaftlichen Eigenständigkeit liegt. Indem wir Speichel lecken, sind wir bereits bespuckt worden und können nicht gegen den Feind hier oder anderswo ausholen, der uns auf eben jene Art und Weise schlägt, hier ankert der Misserfolg aller slawischer Nationen, nicht nur politischer Misserfolg, sondern auch nationaler und national-wirtschaftlicher Misserfolg... Nur zur Verteidigung ausholen wie der polnische ,Bursche', und es ginge. Oder das slawische Volk hat weder Mut noch Kraft ...."

24 „Dass nicht, Intelligenz' jene zu sein pflegt, die die Gegenwart der bei uns entstandenen Lücken verstopft, stets in höchstem Maße erlesen, ist dies nicht die Schuld polnischer Brüder, die ich auch keinesfalls beschuldige."

25 Analphabetismus: Männer über 6 Jahren zu 52\% Analphabeten, Frauen über 6 Jahren zu 60\%, übernommen aus (Gawrecká 2014, S. 99). 
die Darstellung der „polnischen Dummheit“ geformt, die später von weiteren tschechischen Autoren übernommen wird.

Die nationale Zerrissenheit zeigt sich in allen Subsystemen, die die menschlichen Figuren umfassen. Sowohl Polen als auch Tschechen werden in eine höhere und eine niedrigere gesellschaftliche Schicht untergliedert. Während die tschechische Intelligenz wesentliche Züge der Modernisierung ${ }^{26}$ trägt, ist dies bei der polnischen keinesfalls auszumachen. Der Erzähler führt wiederholt vor allen Dingen die Grundelemente des polnischen antisemitischen Adels an, der sich in Bezug auf Besitz und sogar in genetischer Hinsicht im absoluten Zerfall befindet (Sokol-Tůma 1935, Teil 4.-5.: 457). Im Laufe der Handlung wurden der polnische Adel und seine Anhänger zu einer Gruppe von Radikalen, die de facto eine polnische Analogie zur zweiten jüdischen Generation bildet, ${ }^{27} \mathrm{da}$ die radikalisierten Polen dem Feind für Besitz alles verraten, auch den eigenen Namen. Eben dieser Gedanke, in späteren Texten Sokol-Tůmas genauer erörtert, spielt in der weiteren Entwicklung des Bildes der Polen eine wesentliche Rolle. ${ }^{28}$

Ein Spezifikum des Bildes von den Slawen sind nach Auffassung von Sokol-Tůma auch Darstellungen von Frauen als Trägerinnen des Ethnischen. Die Beschreibungen der Frauen sind stark sexualisiert, indem z.B. ihre runden Gesichter und üppigen Körper hervorgehoben werden. Dabei werden zugleich typische ethnische Merkmale definiert. Voller Staunen konzentriert sich der Erzähler systematisch auf die polnischen Frauen, während er bei den tschechischen Frauen weiche Züge, Üppigkeit (Sokol-Tůma 1935, Teil 1.-2.: 171), Lebensfreude und Schönheit (Sokol-Tůma 1935, Teil 3.: 149) nur beiläufig feststellt.

Als wahrhaftig schön werden im Werk vor allem die Polinnen dargestellt, womit sich Sokol-Tůma sowohl gegenüber deutsch als auch tschechisch schreibenden Autoren abgrenzt. Hier sei zum Beispiel die schöne Helena erwähnt,

26 Multikulturelle und tolerante Gesinnung usw.

27 Die sog. zweite jüdische Generation im Werk Sokol-Tůmas ist die Generation von Juden, die ihre eigene Religion und kollektiven Identität verleugnete, wenn es für sie von Vorteil war und sie daraus Profit schlagen konnten.

28 Die Erzählung fokussiert auf die Wiederholung der Darstellung des polnischen Adels, der sich selbst verkauft und verrät, dies ist ein Beleg für den engagierten Aufbau des Werks, das auf das zeitgenössische Element des unbestimmten Verständnisses von nationaler und regionaler Identität der reichen Schicht der polnischen Bevölkerung aufmerksam machen will. Zbigniew Greń verzeichnet diese Problematik vor allem in Großstädten, wie in Krakau, woher sich diese unsichere Wahrnehmung in die Region Teschen u. ä. verbreitet. Im Orig.: „Natomiast warstwy wyższe były mieszane, kosmopolityczne, o niejednolitej świadomości etnicznej (genetycznej, państwowej, regionalnej)“(Greń 200o: 19). 
eine Polin, mit der Chaim "gesündigt“ hat, die Heldin des ersten Teils der Trilogie Černé království:

Jediná děvucha tu byla, jež mu vzdorovala. Byla mladá, ale krásná. Její postava neobyčejné souměrnosti. Obličej, pravý typ čistokrevné Polky, neporušené rasy slovanské. Plavé vlasy, modré oči - ale chudá byla. ${ }^{29}$ (Sokol-Tůma 1935, Teil 1.-2.: 62).

Der Typ der rein slawischen, schönen blonden Frauen durchzieht das gesamte Werk und kontrastiert sogar mit der semitischen Schönheit Deborahs an ihrem Hochzeitstag:

Vedle ní, Polky - družičky se svými pravidelnými obličeji, se svojí zvláštní živostí obličeje, plavými vlasy, v bílých úborech, plných oné jásavé živosti, jíž nemá žádný druhý slovanský národ - snad zacláněly svojí slovanskou krásou, krásu Debořinu. Byly na pohled i krásnější, nikoliv postavou a stavbou těla, ale pravidelností obličeje, leč právě tou svojí nepravidelností byl obličej Debořin, tak nesmírně zajímavý, každého uchvacující. Byla to nepravidelná formace orientálského typu. ${ }^{30}$ (Sokol-Tůma 1935, Teil 4.-5.: 441-442).

Die Trilogie Černé království wäre jedoch selbst nicht imstande, die komplexe Entwicklung des Bildes der Polen im Werk Sokol-Tůmas als Ganzes zu erfassen. Das „Slawische Element“ wird in späteren Romanen zur sog. schlesischen Identität modifiziert. Bei Tschechen, Deutschen, Juden kommt es im Gegensatz dazu nicht zu einer grundlegenden Entwicklung des Bildes. Sokol-Tůma geht in späteren Werken nach den gleichen Schemata wie in der untersuchten Pentalogie vor. Einerseits ist das Bild der Deutschen zu finden,

29 „Es gab nur ein einziges Weib, das mir trotzte. Sie war jung, aber schön. Ihre Statur war von ungewöhnlicher Ebenmäßigkeit. Das Gesicht, das einer reinblütigen Polin, von ungetrübter slawischer Rasse. Blondes Haar, blaue Augen - aber sie war arm.“

30 „Neben ihr überdeckten die Polinnen - Brautjungfern mit ihren gewöhnlichen Gesichtern, mit ihrer besonderen Lebendigkeit des Gesichts, blondem Haar, in weißen Gewändern, voll von ihrer strahlenden Lebendigkeit, die keine andere slawische Nation besitzt - wohl mit ihrer slawischen Schönheit die Schönheit Deborahs. Sie waren beim Anblick auch schöner, nicht in Statur und Körperbau, aber in der Ebenmäßigkeit des Gesichts, außer dass eben diese Unebenmäßigkeit in Deborahs Gesicht, so unendlich interessant, jeden fesselte. Es war eine unebenmäßige Formation des orientalischen Typs.“ 
welches unverändert ist, getrennt und manipulativ, und dessen natürliches Gegengewicht eine Variation des slawischen Elements bildet, also konkret z. B. das schlesische Bild, das sich aus zwei wesentlichen Komponenten zusammensetzt, der tschechischen und der polnischen. Eine solche Entwicklung kann im fünfteiligen Roman Na kresách beobachtet werden, wo die Darstellung des Bildes der Polen vollendet wird.

Die Auswahl des Werks ist nicht willkürlich, da bereits Vojtěch Martínek die Verbindung zwischen den Werken $V$ záríi miliónů und Na kresách wahrnimmt, was auf das Vorhandensein gemeinsamer Ziele und Schnittstellen hinweist, die im engagierten Aufbau des Werks gründen. Es geht um ein nationales Erwachen und eine wirtschaftliche Agitation. Um diese Verbindung deutlich zu machen, wird aus Gründen der Vollständigkeit die folgende Beschreibung der Entwicklung des polnischen Bildes in der Zeit bis zu seiner Stabilisierung hinzugefügt:

Vysoko vyzdvihl [Sokol Tůma] učitelskou buditelskou práci, mravní hodnoty a rozvahu lidového pracovníka. Ale ukazoval ještě na jednu věc: na potřebu hospodářského posílení, jak o tom naléhavě psal již $\mathrm{v}$ románu $\mathrm{V}$ záři miliónů. Veří, že nová hospodářská obroda ve Slezsku rozvirúi i nový národní ruch, rozlítí pokleslé národní uvědomění, naprímí nahnuté páteře. ${ }^{31}$ (Martínek 1957: 92).

Das Werk Na kresách erschien tatsächlich erst im Jahre 1922 in Ostrau, obwohl die nicht umgesetzte Heftausgabe aus dem Jahr 1912 erwähnt wird (Martínek 1957: 88). Auch hier müssen die aktive Tätigkeit Sokol-Tůmas und die aktualisierenden Eingriffe des Autors mit einbezogen werden, die von einer Bearbeitung des Werks bis Anfang der 1920er Jahre zeugen (Martínek 1957: 88). Die Situation ist also die gleiche wie beim ersten Teil der Romantrilogie Černé království, mit dem der angeführt fünfteilige Roman auch den Typ des Erzählers verbindet, der, wenn auch scheinbar im Hintergrund, mit seinen Ansichten aktiv in die Handlung einschreitet und den Leser manipuliert.

Die Interpretation des Romans $\mathrm{Na}$ kresách ist jedoch eine andere. Martínek spricht über eine ausgeprägte Schematisierung des Werks, die in der Verein-

31 „Er [Sokol-Tůma] hob die lehrende erweckende Arbeit, moralische Werte und die Überlegung des menschlichen Arbeiters stark hervor. Aber er verwies auch auf eine Sache: auf den Bedarf an wirtschaftlicher Stärkung, wie er bereits eindringlich im Roman V záři miliónů beschrieben wurde. Er glaubt, dass die neue wirtschaftliche Wiedergeburt in Schlesien auch ein neues nationales Leben entfacht, das gesunkene nationale Bewusstsein erleuchtet, die gebeugten Rücken aufrichtet.“ 
fachung der Thematik und in einfachen Gegensätzen auszumachen sei. Das Werk werde dadurch nicht mehr als glaubwürdig wahrgenommen (Martínek 1957: 89-91).

Hinsichtlich des Genres besteht bei Na kresách eine deutliche Nähe zum deutschen Grenzlandroman. Die gemeinsamen Züge sind vor allem bei einer der Hauptfiguren erkennbar, dem Lehrer Divoký, ${ }^{22}$ der nach Teschen fuhr, um dort mit seiner Tätigkeit aktiv zur Erweckung der Nation beizutragen, dabei die Liebe fand und nach zahlreichen Eskapaden und verlorenen Schlachten den Kampf gegen Klerikalismus, Vorurteile, die „polnische Dummheit“ sowie Germanisierung gewann.

Tatsächlich unterscheidet sich der Roman jedoch durch die primäre Botschaft hinsichtlich der Imagologie keinesfalls von seinen Vorgängern. Das grundlegende Muster ist identisch, die Deutschen bringen eine Germanisierung mit sich und diese ist der Feind alles Slawischen. Während in V zári miliónu die Juden ein Instrument der Germanisierung waren, sind es in Na kresách die Polen, die zu einfältig sind, um sich ihrer Taten bewusst zu sein. Entsprechend dieser Feststellung werden alle Subsysteme erstellt. Weshalb plötzlich einige Polen zum Feind werden, wird erst im zeitlichen Kontext deutlich.

Obwohl der Roman in seinen Grundzügen bereits früher existiert haben muss, wird er in der Zeit des sogenannten tschechoslowakisch-polnischen Konflikts um Teschen zur Veröffentlichung vorbereitet, der (mit unterschiedlicher Intensität) zwischen 1918 und 1958 geführt wurde,,33 wobei als einer der beiden Höhepunkte eben der Beginn der 1920er Jahre gesehen wird. ${ }^{34}$ Der

32 Der wandernde Lehrer ist eine traditionelle Figur im sog. Grenzlandroman, vgl. mit dem Lehrer Ortwin bei Rothacker im Werk Das Dorf an der Grenze.

33 Als Ende des Konflikts wird hier das Jahr 1958 gesehen, da hier der tschechoslowakisch-polnische Vertrag unterzeichnet wurde.

34 Es bestand eine Neigung zur Umsetzung des sog. „plebiscyt na Śląsku Cieszyńskim“, also dem Plebiszit in Teschen, als durch eine Form des Referendums über den Anschluss des Gebiets an den entsprechenden Staat entschieden werden sollte. Obwohl die Tschechoslowakei ursprünglich das Plebiszit ablehnte, ahnte man, dass ein Großteil der Bevölkerung für einen Anschluss an Polen stimmen würde. Letztendlich wurde dieser akzeptiert, um Angriffe der ungünstigen Tissi-Linie zu verhindern. Am Ende kam es nicht zu dem Plebiszit. Die Situation spitzte sich erst im Jahre 1938 merklich zu, als es zu einem weiteren Referendum kommen sollte, welches aber ebenfalls nicht ausgeführt wurde, da Polen am 21.09.1938 die Freigabe des umstrittenen Gebiets als Ergebnis der Sudetenkrise forderte. Folglich wurde entlang der Grenze des umstrittenen Gebiets eine Militäreinheit positioniert und ein zwanzigstündiges Ultimatum ausgesprochen. Angesichts der ausweglosen Situation nahm die Tschechoslowakei das Ultimatum an und das Gebiet wurde geräumt. Information übernommen 
Roman muss also in seiner Zeit aktuell gewirkt haben, und dies nicht nur aufgrund des sogenannten Siebentagekriegs. ${ }^{35}$ Als Ergebnis dieser politischen Veränderungen sieht der Erzähler eine neue Form der Unterdrückung der tschechischen Nation.

Der Aufbau des Werks enthüllt die Idee, dass Polen durch die aktive Manipulation seitens des größten Feindes, der Deutschen, beeinflusst werden. Somit erhält das Bild der Polen seine bestimmenden Züge.

Der Erzähler vermittelt im Schlussteil der gesamten Pentalogie Na kresách den wichtigsten Gedanken, als sich eine der Hauptfiguren, der Lehrer Divoký, nach Prag begibt, um Investitionskapital für die Entwicklung der Region bereitzustellen:

Jel do Prahy. On, laik, bez jména, jel dobývati veliké peněžní ústavy, aby ve Slezsku investováním kapitálu posílily nejen český kraj a lid [...] Neurovnané poměry mezi slovanskými kmeny na Slezsku byly základem pro dynamitové podkopy českých obcí. Skutečnost odpovídala, že za nimi přijdou - ba již jdou - na řadu obce polské. Nenáviděl škorpení obou kmenů, českého i polského, poznávaje, že ve spojení jich k obraně leží společný úspěch. ${ }^{36}$ (Sokol-Tůma 1929: 147).

Vom Standpunkt des Erzählers aus betrachtet ist klar ersichtlich, dass der Zerfall der slawischen Stämme, und somit auch des slawischen Elements allgemein, nicht erstrebenswert ist und den Slawen weder Ruhe noch Entwicklung

aus (Gawrecká 2004: 89-91). Erst nach dem Krieg wurde die territoriale Situation von der Zeit vor der Besetzung Polens wiederhergestellt.

Militärischer, bewaffneter Konflikt zwischen Polen und der Tschechoslowakei von 1919 wegen des Gebiets Teschen. Nach vergeblichem Protest der Tschechoslowakei gegen die Nichteinhaltung des vorläufigen Abkommens, die Überführung der Teschener Bevölkerung in die polnische Armee und gegen die Durchführung von Wahlen im polnischen Sejm griffen die tschechoslowakischen Einheiten an, der Angriff wurde unmittelbar darauf durch die Macht des sog. Dreibunds eingestellt (Klímek 200o: 44).

36 „Er fuhr nach Prag. Er, Laie, ohne Namen, fuhr, um große Geldinstitute zu gewinnen, damit sie in Schlesien durch die Investition von Kapital nicht nur die tschechische Region und das Volk stärken [...] Ungeordnete Verhältnisse zwischen den slawischen Stämmen in Schlesien waren der Grund, warum die tschechischen Gemeinden durch Dynamit untergraben worden sind. Die Wirklichkeit war, dass sie kommen würden ja, bereits kamen -, in einer Reihe der polnischen Gemeinde. Er hasste das Zanken der beiden Stämme, des tschechischen und polnischen, und erkannte, dass in ihrer Verbindung zum Schutze der gemeinsame Erfolg lag." 
bringt. Auch wenn die Romanhandlung etwa 1900 spielt, ${ }^{37}$ so ist der Text vorwiegend auf die vernichtenden Bemühungen der Deutschen konzentriert, Tschechen und Polen zu manipulieren (Sokol-Tůma 1929: 172)..$^{38}$ Die Entwicklung des Bildes der Polen ist im Rahmen des Aufbaus des Werks in dieser Schaffenszeit Sokol-Tůmas vollkommen durch die Vermittlung jener angeblich polnischen Eigenschaften bedingt, die es den Deutschen ermöglichen, die Polen gegen die Tschechen auszuspielen. Eben aus diesen Eigenschaften werden dann die stereotypen Figuren der radikalen, germanisierten polnischen Priester geformt, oder anderer germanisierter Polen. Es kommt somit zu einer Festigung des dargestellten Bildes in einer stereotypen, endgültigen Form.

Im Roman Na kresách wird das Subsystem der Religion auf programmatische Weise entwickelt. ${ }^{39}$ Die Polen, die auf dem dargestellten Gebiet leben, sind häufig tief gläubig und gleichzeitig praktisch orientierte Menschen, in ihrer Einfachheit zweifeln sie jedoch nie an der Autorität der Kirche, die umso mächtiger wird und eine wesentliche Rolle spielt. Der Lehrer Divoký nimmt dies sehr deutlich wahr:

,Tenkrát! - uchopil se opět slova Divoký, žil tento lid životem vlastním. Byl sice sevřen robotou tělesnou. Dnes žije u větší bídě tělesné a horší obránců světovládných snah církve, bojovníků z uplatnění osobních choutek, ani bojovníků kaplanů obránců světovládných stran církve, bojovníků za práva papežova [...], při čemž víra zpravidla pochodí nejhůře, ježto v tomto boji se o víru ani nejedná, pouze o nadvládu bud' germánskou, nebo polskou a tomu slouží církev katolická jako evangelická, česká jako polská.4ㅇ (Sokol-Tůma 1927, Teil 3.: 18).

37 Sokol-Tůma belegt dies selbst in der Fußnote im fünften Teil der Pentalogie (Sokol-Tůma 1929: 227).

38 Auch Przeperski widmet sich der Problematik der Germanisierung in der untersuchten Region. Es ist klar, dass die von Sokol-Tůma empfundene Germanisierung tatsächlich auf beiden Seiten zwischen Tschechen und Polen erlebt wurde (Przeperski 2016: 47). Przeperski spricht sogar über Sympathie von Tschechen gegenüber den Polen, die die Germanisierung erleben (Przeperski 2016: 53).

39 Das Subsystem der Religion der Polen ist in der Überlieferung Sokol-Tůmas stark vereinfacht. Es liegen Studien vor, die grundlegende Unterschiede zwischen Katholiken, Protestanten und ihrer Wahrnehmung der Germanisierung u. ä. belegen. Weiterführend siehe MORYS-TWAROWSKI 2018.

40 „,Diesmal! - begriff Divoký die Worte, lebte dieses Volk ein eigenes Leben. Es war allerdings fest in der Umklammerung körperlicher Arbeit. Heute lebt es in größerer körperlicher Not und unter schlimmeren Verfechtern der Weltherrschaftsbestrebu- 
Eben die oben angeführten Worte verschieben die Kirche mit ihrer Macht vom Subsystem der Religion in die Richtung des Subsystems gemeinsamer menschlicher Züge, denn der Erzähler erörtert de facto im Werk nicht die Glaubensfrage, sondern weltliche Fragen der Überlegenheit einer Nation über eine andere.

Das Subsystem universaler menschlicher Züge durchlief einen grundlegenden Wandel. Es ist interessant, dass es Züge angenommen hat, die Sokol-Tưma ansonsten ausschließlich mit den Juden verbindet, Polen kamen logischerweise in die gleiche Position wie die radikale jüdische Generation. ${ }^{41}$ Sie werden im Werk als Unterdrücker alles Tschechischen dargestellt und dies zu eigenen Nutzen und aufgrund eigener Dummheit: „Obce propadají jedna za druhou do rukou polských nebo německých. Němci používají Poláků jako berana pro utloukání českých obcí, aby je potom snadněji dostali do své moci."42 (Sokol-Tůma 1929: 79). Erst im Schlussteil des fünften Teils der Pentalogie beginnen die Polen langsam, sich ihres Fehlers und ihrer Position als bloße Vorhut der Deutschen bewusst zu werden. Plötzlich dämmert ihnen die Tatsache, dass auch sie im Geiste des „Drangs nach Osten“ letztlich gleichermaßen hinweggefegt werden. Konkret wird dieser Gedanke dann gezeigt, als der örtliche Pfarrer, der die deutsche Sache unterstützt hatte, den Befehl erhält, Deutsch als Amtssprache einzuführen: „Podepsaný úřad oznamuje, že obecní zastupitelstvo se usneslo, aby úřední řečí zavedena byla němčina" (Sokol-Tůma 1929: 200). ${ }^{43}$

ngen der Kirche, Streiter für die Geltung persönlicher Gelüste, Streiter von Kaplanen der Verfechter von Weltherrschaftslagern der Kirche, Streiter für die päpstlichen Rechte [...], wobei der Glaube meist leer ausgeht, da es in diesem Kampf nicht um Glauben geht, nur um Herrschaft, entweder die germanische oder die polnische und dem dient sowohl die katholische als auch die evangelische Kirche, die tschechische wie die polnische."

41 Juden, die ihre eigene Nation, ethnische sowie kulturelle Identität zugunsten des „Mammons“, also der Macht des Geldes, verloren hatten, wobei sie dem Autobild der Tschechen schaden.

42 „Die Dörfer fallen eines nach dem anderen in die Hände von Polen oder Deutschen. Die Deutschen benutzen die Polen als Sündenbock für die Zerschlagen tschechischer Gemeinden, um sie danach schneller in ihre Macht zu bringen.“

43 „Die unterzeichnete Behörde gibt bekannt, dass die Gemeindevertretung beschlossen hat, Deutsch als Amtssprache einzuführen“. Sokol-Tůma selbst zeigt den Gedanken, dass Polen von Deutschen bedroht werden, ebenso wie die Tschechen. Außerhalb des Bereichs des Erzählers in der Fußnote ist von dem Verlust der Möglichkeit die Rede, eine Ausbildung in der Muttersprache zu erhalten: „Stalo se na Slezsku, že v obci zvítězili Němci a rázem prohlásili na celé škole dosud ultraquistické - jako všechny školy ve Slezsku - vyučovací jazyk německý.“ (dt. „Es geschah in Schlesien, dass in der 
In der Komposition des Werks wird die Darstellung der „polnischen Dummheit" weiterhin ausgearbeitet; sie kann bereits früher in der Trilogie Černé království ausgemacht werden, jetzt jedoch erlangt sie wesentliche Ausmaße, da sie hinsichtlich der polnischen Verbindung mit den Deutschen und ihrem Bild eine entscheidende Rolle spielt.

Im Spektrum der deutschen Eigenschaften ist das Element des „Missbrauchs von Nationen" zu finden, dessen zentraler Inhalt die Germanisierung ist, auf subelementarer Ebene sind dann einzelne Formen auszumachen, durch die sich die Germanisierung zeigt. Mit dieser sind die folgenden Subelemente verbunden: Kolonialisierung, Manipulation, Polonisierung, germanisierte Kirche.

Außer der bereits erwähnten Verbindung mit dem deutschen Heterobild wiederholt dann der Erzähler, dass aus Polen allgemein fast nichts Gutes komme: „Tam daleko, z Polska, vycházelo slunce, jasné, zlaté slunce červencové. - To jediné, co odtamtud přichází dobrého -." ${ }^{44}$ (Sokol-Tůma 1927, Teil 3.: 124).

Der Gesamtaufbau des Werks beinhaltet Elemente, die Polen auf die Ebene der radikalisierten Juden stellen, und dies vorrangig aus Sicht der Kolonialisierung, im Sinne der Besetzung neuer Gebiete, der eigenen Expansion. Dies zeigt die Sprache des Lehrers Divoký:

[získané území] za nějž nemusil by se stydět ani Srukl Bauchbrenner z Ostravy - není-li jeho vlastnictvím. Pozemky zde skupují nepozorovaně cizí lidé. [...] A náš lid směje se a vtipkuje po straně, že napálil ,cuzáka. Je i rád, že se podobné neúrodné půdy zbavil. A tito kupující nejsou nic jiného, než zřízenci závodů uhelných, nejčastěji židé nebo Poláci. [...] Tímto způsobem je množství jiter půdy kolem Doloplaz dnes již v rukou cizích a původní majitelé, nevědoucí o účelu, k jakému se děje toto zakupování, byli už o tisíce připraveni. Toto je novodobé loupení starých loupežných rytírư. ${ }^{45}$ (Sokol-Tůma 1927, Teil 3.: 106).

Gemeinde die Deutschen siegten und sogleich in der gesamten Schule, die bis dahin utraquistisch waren - wie alle Schulen in Schlesien -, Deutsch zur Unterrichtssprache erklärten.“) (Sokol-Tůma 1929: 200).

44 „Dort in der Ferne, aus Polen, ging die Sonne auf, eine helle, goldene Julisonne. - Das einzige, was von dorther Gutes kommt-."

45 „[besetztes Gebiet] für das sich nicht einmal Srukl Bauchbrenner aus Ostrau schämen musste - wenn es nicht sein Eigentum ist. Hier kaufen unbeobachtete fremde Leute Grund und Boden. [...] Und unser Volk lacht und scherzt nebenbei, dass es den ,Zugereisten' überlistet hätte. Auch ist es froh, sich derlei unfruchtbaren Bodens zu entledigen. Und diese Käufer sind nichts anderes als Angestellte von Kohlebetrieben, meist Juden oder Polen. [...] Somit ist ein Großteil des Ackerlands um Doloplazy 
Der Erzähler betont auch die Dummheit, das Unverständnis gegenüber der Tatsache, dass die Slawen nur gemeinsam den großen deutschen Feind bezwingen können. Es wird die Aufgabe von Zeitungen und Propaganda hervorgehoben, einfache, unkritische Leute zu beeinflussen:

Polské noviny zaujaly jakési štvavé stanovisko proti faráři, že Poláci v Záhlubku byli skoro vybízení zprostit se sami faráře za každou cenu. Různí lidé sem přicházeli, různé řeči vedli. Hospody po výplatě obsadili a vykládali, jak Poláci jsou utiskováni od Čechů, že lepší Němec ,bo Niemec nieuciská Polaka, ale Čech psiakrev bestia hromská kradze dzieči polske na Šlonsku, kradzie polskie dusze i wszystko Takové rozpravy byly vedeny. Tímto směrem a jak obecním výborem, tak tiskem polským rozdmychované, ba i hmotně podporované. ${ }^{46}$ (Sokol-Tůma 1929: 234).

Der Roman Na kresách beschreibt die polnische Ethnie als Zusammenschluss von Einzelnen, die sich in fester Umklammerung durch die Kirche befinden. Diese wird jedoch nicht mehr als Institution beschrieben, die sich um das Seelenheil der Menschen sorgt, sondern als Vereinigung radikaler Priester, die das Volk in die deutsche Hegemonie führen. In dem Auszug ist ebenfalls die Gegenwart des Juden in der stereotypisierten Form zu finden, eine Figur, die für die abschließende Schaffensphase Sokol-Tůmas charakteristisch ist:

Polští kněží, at katoličtí nebo evangeličtí, postupovali útočně proti všemu českému, hlásajíce vyhlazovací válku všude tam, kde mohli rozdmychat požár odporu. Polský negramotný lid věří svým kněžím, že ,Šlonsk ojezyzna polská jest' a podporován štvavým tiskem polských novin, jakož i knížkami a spisky, falešně dějiny Slezska kreslícími, stával

heute schon in den Händen Fremder und die ursprünglichen Besitzer, ahnungslos, zu welchem Zwecke das Kaufen betrieben wird, wurden bereits um Tausende gebracht. Dies ist die neuzeitliche Jagd alter Raubritter."

46 „Die polnische Zeitungen nahmen einen hetzerischen Standpunkt gegen Pfarrer ein, dass die Polen in Záhlubek fast dazu aufgefordert wurden, den Pfarrer um jeden Preis loszuwerden. Verschiedene Leute kamen hierher, sie hatten unterschiedliche Ansichten. Die Wirtshäuser waren voll belegt und erklärten, wie Polen von Tschechen unterdrückt werden, dass der bessere Deutsche, denn der Deutsche unterdrückt keinen Polen, aber der Tscheche ,psiakrev', die Bestie stiehlt die Kinder in Schlesien, stiehlt die polnischen Seelen und alles.' Solcherlei Debatten wurden geführt. Durch diese Richtung und sowohl durch den Gemeinderat als auch durch die polnische Presse entflammt, ja sogar massenweise unterstützt.“ 
se úporným nepřítelem všeho českého. Stalo se, že přijel do Záhlubku kočár, v němž byli dva, tři páni. Pili v hospodě u žida Himelbeina nebo Scheinduta a za chvilku tam bylo veselo. Pil, kdo přišel, Páni platili. ${ }^{47}$ (Sokol-Tůma 1927, Teil 4.: 134).

\subsection{August Scholtis}

August Scholtis wird als weiterer bedeutender Autor von Romanen der Zwischenkriegszeit in der Region Ostravsko erachtet. ${ }^{48}$ Sein Werk Das Eisenwerk (1939), in der tschechischen Übersetzung Železárny (1940), stellt für diese Untersuchung eine einzigartige Synthese künstlerischer und autobiografischer Züge dar. Vor allem die frühen Jahre Scholtis' werden mit der Bewunderung Prusks und dem Gefühl der Verbundenheit mit ihm verknüpft, da er während einer Volksabstimmung 1920 für die dauerhafte Eingliederung Oberschlesiens in das deutsche Land stimmte. Die Sympathie mit Prusk, zweifelsohne verbunden mit den Erfahrungen am Adelshof Karl Max von Lichnowskys, kann somit einen neuen Blickwinkel auf die Formung des polnischen Heterobildes während der Zwischenkriegszeit eröffnen.

Dieses wird umso bunter und facettenreicher, als Scholtis, übrigens wegen seiner Weigerung, während des Dritten Reiches in die Reichsschriftumskammer

47 „Die polnischen Priester, ob katholisch oder evangelisch, gingen aggressiv gegen alles Tschechische vor, riefen einen Krieg der Ausrottung überall dort aus, wo sie das Feuer der Abneigung entfachen konnten. Das polnische Volk, das weder lesen noch schreiben konnte, glaubt seinen Priestern, dass ,Schlezien immer polnisch war. Es wird zum hartnäckigen Feind alles Tschechischen durch die hetzerische Presse der polnischen Zeitungen, sowie durch Bücher und Schriften, die die falsche Geschichtsschreibung Schlesiens gezeichnet haben. Es geschah, dass eine Kutsche nach Záhlubek kam, darin waren zwei, drei Herren. Sie tranken im Wirtshaus beim Juden Himelbein oder Scheindut und nach einer Weile ging es dort fröhlich zu. Es trank, wer kam, die Herren zahlten."

48 August Scholtis (1901, Bolatice (Hultschiner Ländchen) - 1969, Berlin) ist ein Autor, der bereits als Kind eine enge Bindung zum Hultschiner Ländchen hatte. Er beschäftigte sich mit der Verdrängung der Mehrsprachigkeitskultur in der Region Ostravsko sowie mit sozialen Themen. Während der Zwischenkriegszeit trugen seine Werke einen mythologisierenden Charakter, dennoch erhielt er nach Beginn des Dritten Reiches ein Publikationsverbot. Weiterführend siehe Deutsche Literatur der Zwischenkriegszeit im tschechischen Schlesien. 1918-1938 (2002). Für weitere Informationen siehe neuere Literatur in Český a nèmecký sedlák v zrcadle krásné literatury 1848-1948 (2014), oder Historik a literát v provincii (2018). 
einzutreten, ein Publikationsverbot erhielt ${ }^{49}$, womit er sich von dem anderen regionalen deutschen Schriftsteller Gottfried Rothacker unterscheidet. ${ }^{50}$

Das polnische Heterobild scheint bei Scholtis stark unstrukturiert, da das Werk keine konkreten polnischen Figuren beinhaltet. Somit ist das Heterobild zur ausschließlichen Wahrnehmung „von außen“ verurteilt. Die Abwesenheit polnischer Figuren verursacht ebenso die Unfähigkeit dieses Bildes mit dem komplexen Aufbau des Werkes tiefer zu interagieren, denn es gibt hier keine Figuren, die alle erwähnten Stereotypen stören können. Das Bild der Polen tritt daher nur auf der Ebene sprachlicher Stereotypen und petrifizierter Fragmente auf, über die im Aufbau des Werks nicht verhandelt wird.

Es handelt sich um ein äußerst deformiertes und stark manipulatives Bild. Das einzige neutrale Element in der gesamten Struktur des Bildes ist die Darstellung einer geheimnisvollen Region / eines Landes, die der Erzähler ausschließlich zur Beschreibung eines geografischen Gebiets als „das polnische Geheimnis“ nutzt (Scholtis 1939: 65).

Die übrigen Subsysteme und Elemente sind durchgehend negativ, mit Verweisen auf Schmutz und Niedrigkeit, wie z.B. „Dreck“ (Scholtis 1939: 100). Referenzen gegenüber dem namenlosen Polen werden ausschließlich auf der Ebene der Ausgestaltung polnischer Dummheit konstatiert: „Ein Pole quatscht und weiß nicht, was er quatscht“ (Scholtis 1939: 104), wobei ähnliche Äußerungen von deutschen sowie tschechischen Figuren gemacht werden.

Das Bild Polens ist ebenso mit der Angst vor der Gefahr verbunden, da die Polen laut Erzähler den industriellen Fortschritt bedrohen würden, den im Roman die Deutschen repräsentieren:

Es hieß, drüben im Halizischen, im Russisch-Polnischen gäre es. Die Polen seien mit ihrem Schicksal unzufrieden und ihre Unzufriedenheit drohe hinüberzuspringen in den planenden, arbeitenden, industriellen Westen. (Scholtis 1939: 352).

Die Mehrheit negativer Elemente kulminiert vor allem in den Dialogen der Figuren sowohl deutschen als auch tschechischen Ursprungs, allerdings sind auch im Bereich des Erzählers auf wahrscheinlich unbewusster Ebene kompo-

49 Vgl. und weiterführend siehe: Deutsche Literatur der Zwischenkriegszeit im tschechischen Schlesien. 1918-1938 (2002).

50 Es kann also vorausgesetzt werden, dass seine Gestaltung des polnischen Bildes von der stark ideologischen Auffassung radikaler nationaler Sozialisten auf interessante Weise abgegrenzt werden kann. 
nierte stereotype Parallelen zu finden. Es kann der Vergleich von Zbytkovice (es handelt sich im Buch um eine Überarbeitung der realen Vorlage Vítkovice) mit einer polnischen Frau beobachtet werden. Der Autor betont die Schwäche des ursprünglich bedeutungslosen Städtchens, das seine anschließende Entwicklung den Deutschen verdankt:

Von ihm liegt Bitkowitz, die wachsende Stadt. Sie hebt sich aus der Ebene, eine unförmige Frau, barfuß, mit schmutzigen Füssen von den polnischen Bergen pilgernd zu den Deutschen, die ihr ein Kleid antun, ein Seidenkleid. Eines Tages wird aus dieser Frau etwas geworden sein. (Scholtis 1939: 272).

Scholtis' Werk verbindet die Konstruktion des Bildes der Polen mit dem Bild einer schwachen Frau, die nicht ohne deutsche Hilfe auskommt. Diese Darstellung von Polen ist auch anderen untersuchten Autoren eigen, weshalb hier deutlich wird, dass es sich um ein charakteristisches Konstruktionselement des Heterobildes der Polen in Romanwerken der entsprechenden Periode handelt.

\section{Fragmentarische Darstellung}

Für die vollständige Abbildung des komplexen Kontexts der Periode in Bezug auf das untersuchte Gebiet ist es ratsam, die Problematik anderer Werke auszuführen, in denen das Bild Polens behandelt wird. Im Verlauf der Untersuchung hat sich gezeigt, dass die Konstruktion dieses Bildes für andere Autoren nicht programmatisch ist. Das Bild Polens taucht somit bei den folgenden Schriftstellern nur auf fragmentarischer Ebene auf, nicht in einem ausgearbeiteten System, wie dies in den oben untersuchten Werken der Fall war. Bei einigen Autoren fehlt es gänzlich und auch diese Feststellung wird als bedeutsam angesehen, und es wird versucht, sie aus dem Kontext heraus zu begründen.

\subsection{Tschechische Fragmente}

Vojtěch Martínek ${ }^{51}$ verfasste in der Zwischenkriegszeit eines der eindrucksvollsten Werke seines gesamten literarischen Schaffens; es handelt sich um die

51 (1884 Brušperku - 1960 Ostrau). Er stammte aus einer armen Familie und besuchte das Gymnasium in Ostrau. Er veröffentlichte z.B. in der Zeitung Ostravský deník. Den Mittelpunkt seines Schaffens bilden Werke mit sozialer Thematik. Weiterführend in Literární slovník severní Moravy a Slezska (2001). 
Trilogie Černá země (1932). Die einzelnen Romane dieses Zyklus heißen Jakub Oberva (1926), Plameny (1929) und Zemé duní (1932). Gerade durch die Auswahl der genannten Trilogie bietet sich die einzigartige Gelegenheit, die Ausgestaltung des Heterobildes über die Zeit hinweg zu betrachten. Wenn ebenfalls die Entstehungszeit des Romans berücksichtigt wird, wird die Entwicklung von Anfang der 1920er Jahre bis in die frühen 1930er Jahre betrachtet.

In der Trilogie Černá země befindet sich hinsichtlich der Häufigkeit des Auftretens das umfangreichste Heterobild der Deutschen. Außerdem ist noch ein relativ klar strukturiertes Heterobild der Juden erkennbar. Roma und Polen sind im Werk ausschließlich in Form von unstrukturierten Stereotypen zu finden..$^{52}$

Die polnischen Fragmente verweisen vor allem auf Motive der „Unreinheit, Hässlichkeit“. Das Bild der Polen weist keine systematischen Elemente auf, es sind zufällige Erwähnungen über hässliche polnische Frauen (Martínek 1965, Jakub Oberva: 46, 69) und möglicherweise zeitweise vorkommende, unsystematische und negative Anspielungen auf Polen im Bereich der Figuren vorzufinden: „[...] Ale Polaci, [...] Tuž co - pšakrev, zatracene hovada. “" 1965 - Země duní: 79).

Ende der 1930er Jahre wurde das Bild der Polen noch flüchtig von Karel Dvořáček angesprochen. Das vom Autor ${ }^{54}$ mehrfach überarbeitete Werk František chce býti spravedlivý entstand bereits ab der zweiten Hälfte der 193oer Jahre. Die damalige Zensur und die fortwährende Anpassung, die das Werk im Laufe einiger Jahre durchlief, führten dazu, dass der Roman zu einem Umbruchspunkt für die Darstellung des Bildes bei Dvořáček wurde. Diese Veränderung in der Struktur jenes erwähnten Werkes spiegelt sich bereits in zeitgenössischen Kritiken wider. Es ist von einer Veränderung vom sozialen Roman zur „neutralen“,

52 Noch stärker imagologisch intakte Texte stellen die Romane von Ludmila Hořká dar (geb. als Marie Šindelářová, 1892 Dvořisko - 1966 Troppau, Hultschiner Ländchen). Aufgrund des Schaffens in Troppau kam die Autorin jedoch nicht mit der galizischen Migrationswelle in Berührung. Ihr autobiografisch gefärbtes Schaffen, die Romane Doma (1943) und $\check{R} e k a$ (1946), fallen in die untersuchte Zeit, und beinhalten außer dem Schmuggel (Hořká 1946: 21) keine ethnotypischen Systeme oder Fragmente.

53 „[...] Aber Polen, [...]. Stählt etwas - pšakrev, verdammte Rindviecher.“

54 In diesem Teil wird Dvořáček als Autor ausgewählt, der die Tendenzwelle vertritt, die sich gar nicht mit der Darstellung eines Heterobildes beschäftigt. Aufgrund des Umfangs werden weiterhin weder Glazarová noch Třenecký betrachtet, die ebenfalls keine Bilder formen, es kann bei ihnen vielmehr von Imagotypen gesprochen werden, und dies vor allem aufgrund des Charakters ihrer ausgewählten Prosa, die in das ausgewählte Material fällt (Erinnerungs- und Bilanzcharakter bei Glazarová und der schematisch-soziale Charakter der Romane von Třenecký). 
idealisierten Erzählung die Rede, wobei sich Dvořáček von der Erörterung im breiteren gesellschaftlichen Kontext abwendet (Durčák 1966).

Deshalb ist im Roman vorrangig das Bild einer unbestimmten sozialen Gemeinschaft zu finden, deren Darstellung an der konzeptuellen Grenze der Begriffe Imagotyp / Ethnotyp schwankt.

Auf den Begriff Ethnotyp wird erst bei der Darstellung der Heteroelemente der unterschiedlichen Ethnien innerhalb von Dvořáčeks Konzeption der Multikulturalität der Region Ostravsko eingegangen. Dvořáček formt also nicht konkret das Bild von Polen, sondern wählt ein unstrukturiertes sekundäres Element. Es geht zum Beispiel um die wiederholte Darstellung eines einfältigen, sehr hässlichen polnischen Mädchens (Dvořáček 196: 173-174). Dvořáčeks Erzähler betont die polnische Herkunft des Mädchens und kehrt wiederholt zu ihr zurück (Dvořáček 1966, S. 225), obwohl sie in der Erzählung keine bedeutungstragende Rolle spielt, sie wird als Maschine beschrieben, als Prostituierte, bezahlt mit wertlosen Eisenringen, sie steht also weit unter der gesellschaftlichen Position der tschechischen Prostituierten. Weshalb dies so ist, geht allerdings aus dem Werk nicht hervor.

\subsection{Deutsche Fragmente}

Maria Stona ${ }^{55}$ ist neben Ilse Weber und Marie von Ebner-Eschenbach, deren Werk nicht dem Genre, den territorialen oder thematischen Kriterien dieser Studie entspricht, die bedeutendste deutsche Schriftstellerin der Zwischenkriegsliteratur in der größeren Region Ostravsko. ${ }^{56}$ Ihr Roman Vor dem Sturz (1934) wurde auch ins Tschechische übersetzt (Před pádem 1935).

Das Thema der Untreue und des Sturzes einer Frau und ihrer Familie wird aus der Perspektive der Hauptheldin mit autobiografischen Elementen erzählt. Im Hinblick auf die Imagologie ist der Text vollständig intakt. Im Roman finden wir nur eine Darstellung des allgemeinen Imagotyps der hohen sozialen Schicht und der Aristokratie, zu der die Hauptfigur am Anfang auch gehört.

55 (1861 Schloss Triebitz - 1944 ebenda) wuchs seit ihrer Kindheit in einem Schloss auf. Sie ist Autorin von Romanen und Erzählungen mit sozialen und Gender-Themen, ihre Gedichte konzentrierten sich auf das private Leiden des Einzelwesens in der Gesellschaft.

56 Neben Maria Stona kann auch Ernst Wolfgang Freissler (1884 in Troppau - 1937 Olbersdorf) erwähnt werden. Er schrieb jedoch in Troppau, wo er keine starke Migrationswelle aus Galizien miterleben konnte. Sein Roman Junge Triebe (1922) ist stark transnational orientiert. Es hat sich gezeigt, dass Freissler nur das Autobild der Deutschen in seinem Werk konstruiert. 
Jünger als Maria Stona ist Gottfried Rothacker. ${ }^{57}$ Das Werk dieses Autors wurde stark ideologisch motiviert. Sein bekanntestes Werk, Das Dorf an der Grenze (1936), das Ende der 1930er Jahre zum Bestseller wurde, ist ein autobiografisch gefärbter Roman, da Rothacker selbst als Lehrer in kleinen sudentendeutschen Dörfern auftritt.

Das zentrale Thema des Werks ist die Darstellung des mährisch-schlesischen Dorfes Skopolnica / Schatzdorf, der Bewohner, ihrer national-sozialen Probleme in Wechselwirkung mit der Ankunft des jungen Lehrers Ortwin Hartmichel.

Bei diesem konkreten Autor darf ebenfalls nicht der spezifische literarische Kontext des auf Deutsch verfassten Schaffens übersehen werden, das stark durch die „Blut-und-Boden-Literatur“ sowie das Genre des Grenzlandromans ${ }^{58}$ u. a. beeinflusst ist. Hier kann eine starke ideologische Färbung angenommen werden, ${ }^{59}$ da sich in der auf Deutsch verfassten Literatur der 1930er Jahre u a. ein ideologischer Schreib- und Denkstil herausbildet, der eng mit den Studien von Adalbert Schmidts Sudetendeutsche Dichtung der Gegenwart (1938) zusammenhängt.

Die Hauptintention des Autors zeigt sich durch den Aufbau des Autobildes von Deutschen. Es wurde die Gefahr dargestellt, der die in Grenzgebieten lebenden Deutschen trotzen müssen. Da die Gefahr ausschließlich von Tschechen ausgeht, wird im Roman kein Bild der Polen konstruiert.

\section{Zusammenfassung}

Die vorliegende imagologische Analyse erarbeitete einige grundlegende Aspekte, die für die Ausrichtung der imagologischen Forschung in manipulativen

57 Geboren als Bruno Nowak (1901 Troppau - 1940 Berlin). Er trat bereits 1926 in die NSDAP ein. Die deutsche Autorenenzyklopädie führt auch eine Liste von Termini an, die maßgeblich die Auslegung seines Werks bestimmen: „Auslandsdeutschtum“, „Grenzlandkampf“ und „Heldenverehrung“. Weiterführend siehe Deutsche biographische Enzyklopädie \& Deutscher biographischer Index 2001:568. Rothacker war in der Zeit des sog. Dritten Reichs ein sehr beliebter und geschätzter Autor; er wurde z.B. mit dem Hans-Schemm-Preis ausgezeichnet.

58 Der Grenzlandroman selbst kann dann nach Rinas in drei Typen unterteilt werden: a) der Grenzlandroman aus der Perspektive des Grenzgebiets b) der Grenzlandroman als Form, die den Konflikt zweier Sprachen auf einem Gebiet thematisiert c) der Grenzlandroman als Genre mit der Thematik des nationalen Konflikts. (Rinas in Becher 2017:307-308).

59 Konkret im Zusammenhang mit dem Stil des Autors spricht Budňák von der sog. „statischen Erzählung“ (Budňák 2007:185). 
und primär ideologischen Strukturen wertvoll sind. Der Fokus lag vor allem auf der Enthüllung grundlegender Stereotypen der Darstellung von Heterobildern der Polen in ausgewählten Werken der tschechischen und deutschen Literatur der Zwischenkriegszeit aus der näher definierten Region Ostravsko derselben Periode. Es stellte sich heraus, dass die zeitliche Eingrenzung auf die Periode von 1918 bis 1939 für das literarische Werk nicht gänzlich bestimmend ist, weshalb diese Problematik näher abgesteckt wurde und es zu bestimmten Überlappungen kam, die weiter oben beschrieben wurden.

Das Bild der Polen ist in der Romanprosa nur äußerst sporadisch vertreten. Auf tschechischer Seite kann zunächst eine komplexe Darstellung des Heterobildes der Polen bei František Sokol-Tůma verzeichnet werden, die sich durch einen persuasiven Charakter auszeichnet und die Einheit des Slawentums propagiert, und eben diese wird im späteren Werk durch die Elemente gestört, die auf die deutsche Manipulation mit Polen hinweisen.

Die Autoren sind in ihren Konstruktionen des polnischen Heterobildes nicht in der Lage, sich von den Elementen der „Dummheit“ und „Rückständigkeit“ zu lösen, wie aus mehreren Quellen hervorgeht. Einerseits geht es um den Analphabetismus der Bevölkerung der primär dargestellten Gebiete (Immigranten aus Galizien und angrenzender Gebiete), „Dummheit“ ist ebenso mit rassenideologisch motiviertem Antisemitismus verbunden sowie mit der vermeintlichen polnischen Rolle hinsichtlich der Germanisierungsfrage. Die Polen werden somit, insbesondere im Werk von Sokol-Tůma, zu aktiven Helfern der Deutschen in der Unterdrückung der Nationen. Dieser Gedanke findet auch im zeitgenössischen lyrischen Schaffen der Region seine Resonanz, z.B. bei Petr Bezruč, auf den Sokol-Tưma sich im Werk Na Kresách sogar beruft. In der deutschen Literatur sind die Furcht vor polnischen Vorurteilen sowie die Bemühungen zu finden, den industriellen Fortschritt umzukehren, den die Deutschen in die Region Schlesiens bringen.

Die Darstellung der „polnischen Schwäche“ ist ein weiteres grundlegendes Phänomen, verbunden mit der Metapher der sexualisierten Darstellung des weiblichen Geschlechts, das unter den Autoren männlichen Geschlechts stereotyp genau mit der geschwächten Position der Polen verbunden wird. Diese Metapher hat diesen Untersuchungen zufolge auf tschechischer Seite ihren Ursprung in historischen Umständen, während sie auf deutscher Seite von der Vorstellung einer industriellen Überlegenheit vor allem der ursprünglich preußischen Bevölkerung herrührt (im Werk von A. Scholtis).

Die komplexe Strukturiertheit des Polenbildes geht in den folgenden Jahren zugunsten einer fragmentarischen, stereotypen Darstellung von Unreinheit, Dummheit und Hässlichkeit in den Werken weiterer tschechischer Autoren 
zurück (K. Dvořáček, V. Martínek). Sofern tschechisch schreibende Autoren das Bild der Polen überhaupt reflektierten, so geht es lediglich um eine verengte Darstellung, die sich auf galizische Polen konzentriert. Weitere deutsch schreibende Autoren formen in den untersuchten Werken das Polenbild nicht einmal auf fragmentarischer Ebene. Bei älteren Autoren (M. Stona, E.W. Freissler) liegt der Grund in der supranationalen Motivation der Werke sowie der primären Darstellung sozialer und geschlechterbezogener Imagotypen, während bei dem jüngeren Autor Rothacker das Desinteresse am Bild der Polen durch die ideologische Struktur des Werks zu begründen ist, das vor allem zum Kampf gegen alles Tschechische auffordert.

Maßgeblich scheint ebenso die konkrete territoriale Zugehörigkeit des Autors / der Autorin, also die regionale Grundlage seines / ihres Schaffens. Somit kann geschlussfolgert werden, dass die weitere Region Ostravsko hinsichtlich der Ausformung des Polenbildes in zwei eigenständige Bereiche unterteilt werden muss. Zunächst geht es um Ostrau und die angrenzenden östlichen Gebiete (z. B. Teschen), wo sich die galizische Migration in vollem Umfang bemerkbar machte, wodurch die oben beschriebenen Stereotypen aktiviert wurden. An zweiter Stelle wird zwischen Galizien und Troppau unterschieden, wo sich vor allem die deutschen Autoren konzentrierten, die das Bild der Polen aus den oben angeführten Gründen nicht thematisieren, aber auch, da die Migrationswelle dieses Gebiet nicht betraf. Die einzige Ausnahme bildet August Scholtis, der allerdings notwendigerweise eine petrifizierte Form des Bildes präsentiert.

\section{| Quellen}

\section{PRIMÄRQUELLEN}

Dvořáček, Karel: František chce býti spravedlivý. Ostrava: Profil, 1966.

Hořká, Ludmila. Doma. Praha: Vyšehrad, 1943.

Hořká, Ludmila. Řeka. Praha: Vyšehrad, 1946.

Martínek, Vojtěch. Černá země: Jakub Oberva. Ostrava: Profil, 1965.

Martínek, Vojtěch. Černá země: Plameny. Ostrava: Profil, 1965.

Martínek, Vojtěch. Černá země: Země duní. Ostrava: Profil, 1965.

Rothacker, Gottfried: Das Dorf an der Grenze. München: Albert Langen/Georg Müller, 1936.

Stona, Maria. Před pádem. Ostrava: Př́loha Posledního ostravského deníku, 1935. Stona, Maria: Vor dem Sturz. Wien: Europ. Verl. 1934.

Scholtis, August. Das Eisenwerk. Berlin: Wolfgang Krüger Verlag, 1939. 
Scholtis, August. Železárny. Brno: Fr. Borový, 1940.

Sokol-Tůma, František. Na kresách - díl 1.-3. Mor. Ostrava: Al. Zelinka, 1922.

Sokol-Tůma, František. Na kresách - díl 3. Praha: Julius Albert, 1927.

Sokol-Tůma, František. Na kresách - díl 4. Praha: Julius Albert, 1927.

Sokol-Tůma, František. V záři milionů - díl 1.-2. Praha: Julius Albert, 1935.

Sokol-Tůma, František. V záři milionů - díl 3. Praha: Julius Albert, 1935.

Sokol-Tůma, František. V záři milionů - díl 4.-5. Praha: Julius Albert, 1935.

\section{SEKUNDÄRQUELLEN}

Adámková, Lenka. (2011): „... schrecklich fremd, dennoch anziehend“ (Škvorecký): zum Bild des Rotarmisten in ausgewählten Texten der tschechischen und (ost) deutschen Literatur nach 1945. New York: Peter Lang, 2011.

Becher, Peter, Steffen Höhne, Jörg Krappmann a Manfred Weinberg, ed. Handbuch der deutschen Literatur Prags und der Böhmischen Länder. Stuttgart: J.B. Metzler Verlag, 2017.

Beller, Manfred. Imagology: the cultural construction and literary representation of national characters : a critical study. Amsterdam: Rodopi, 2007.

Borovička, Lukáš, Strobach, Vít. Jak na (literární) antisemitismus?: Modelová studie: antisemitské reprezentace u Františka Sokola-Tůmy. Dějiny - teorie kritika. 14(1). S. 43-77.

Budňák, Jan. Das Bild der Tschechen in der deutschen Literatur aus Böhmen und Mähren. Dissertation, 2007.

Černá země: časopis lidově výchovný. 1936, 12(4-5).

Corbineau-hoffmann, Angelika. Einführung in die Komparatistik. 2., überarb. u. erw. Aufl. Berlin: Schmidt, 2000.

Durčák, J. Cesta Karla Dvořáčka. In: Těšínsko. Český Těšín, 1966, 10(1).

Dyserinck, Hugo. Ausgewählte Schriften zur Vergleichenden Literaturwissenschaft. Berlin: Frank \& Timme, 2015.

Dyserinck, Hugo. Von Ethnopsychologie zu Ethnoimagologie. Über Entwicklung und mögliche Endbestimmung eines Schwerpunktes des ehemaligen Aachener Komparatistikprogramms, in: Neohelicon 29.1 (2002), s. 57-74.

Gawrecká, Marie. Československé Slezsko mezi světovými válkami 1918-1938. Troppau: Schlesische Universität, 2004.

Gawrecká, Marie. Středoevropské migrace v 19. století a jejich národnostní a kulturní aspekty. Troppau: Schlesische Universität, 2014.

Greń, Zbigniew. Śląsk Cieszyński: dziedzictwo językowe. Warszawa: Sławistyczny Ośrodek Wydawniczy, 2000.

Klímek, Antonín. Velké dějiny zemí Koruny české. Svazek xıII. Prag: Paseka, 2000.

Leerssen, Joseph, Theodor. Imagology: On using ethnicity to make sense of the world. Iberic@l,Revue deétudes ibériques et ibéro-américaines. 2016, (10), s. 13-31. [zit. 2018-04-11]. Erreichbar: https://tinyurl.com/y6k2nlkc. 
Malíř, Jiří. Pavel Marek. Politické strany: vývoj politických stran a hnutí v českých zemích a Československu 1861-2004. Brno: Doplněk, 2005.

Martínek, Vojtěch. František Sokol Tưma člověk a dílo. Brünn: Moravské kolo spisovatelů, 1926.

Martínek, Vojtěch. František Sokol Tưma život a dílo. Ostrau: Krajské nakladatelství v Ostravě, 1957.

Mehnert, Elke. Vademekum der Imagologie. Chemnitz, 1997.

Mehnert, Elke. Grenzüberschreitungen. Zum Problem der Transgredienz in der Imagologie. In Deutsch an der Grenze. Pilsen: Západočeská univerzita v Plzni, 2016. s. 15-23.

Meyers Enzyklopädisches Lexikon, Bund 1-25, GrosHe, Mannheim, Wien, Zürich, 1971-1979, s. 629

Morys-Twarowski, Michael. The Relationship Between Religion, Language and Nationality Using the Example of Village Mayors in Cieszyn Silesia in 1864-1918. History, Issues, Problems. Praha: Univerzita Karlova, Filozofická fakulta, 2018, 17(2), 149-161.

Mukařovský, Jan. Záměrnost a nezáměrnost v umění. In: Strukturalistická knihovna, Sv. 4., Brno 200o, s. 353-388, [online], [zit. 2019-03-16], unter: https://tinyurl.com/y24c7oup.

Nünning, Ansgar, Jiří Trávníček a Jiří Holý, ed. Lexikon teorie literatury a kultury: koncepce - osobnosti - základní pojmy. Brünn: Host, 2006.

Przeperski, Michał. Nieznośny ciężar braterstwa: konflikty polsko-czeskie w xx wieku. Kraków: Wydawnictwo Literackie, 2016.

Schubert, Gabriella. Wolfgang. Dahmen. Bilder vom Eigenen und Fremden aus dem Donau-Balkan-Raum: Analysen literarischer und anderer Texte. München: Südosteuropa-Gesellschaft, 2003.

Slovník české literatury po roce 1945 [online]. 2006 [zit. 2018-07-26], unter: https://tinyurl.com/y22vcaa5.

Swiderska, Malgorzata. Theorie und Methode einer literaturwissenschaftlichen Imagologie Dargestellt Am Beispiel Russlands in Literarischen Werken Heimito Von Doderers. Frankfurt: Peter Lang GmbH, Internationaler Verlag der Wissenschaften, 2013.

Ullrich, Josef. Das Heim der Dichterin Maria Stona. In: Deutschmährische Heimat. Brünn, 1926, 11-12, s. 145-150. [online], [zit. 2019-03-16], unter: https://tinyurl.com/y2vypzp2.

Veberová, Veronika a David Skalický, ed. Jazyky reprezentace. Prag: Akropolis, 2014.

Veberová, Veronika a David Skalický, ed. Jazyky reprezentace 2. Prag: Akropolis, 2014.

Voltrová, Michaela (2015): Studien zur komparatistischen Imagologie. Berlin: Frank and Timme. 


\section{| Abstract \\ LUKÁš PĚCHULA \\ Das Bild der Polen als Heterokonstruktion in Zwischenkriegsromanen der Region Ostravsko: Tschechisch-deutsche imagologische Untersuchung}

Die vorliegende Studie zielt darauf ab, die Strukturen des Heterobildes der Polen in den Romanen der größeren Region Ostravsko zwischen zwei Weltkriegen zu entschlüsseln. Es geht um eine komparative Analyse, die polnische Ethnotypen in den Werken deutscher und tschechischer Autoren dieser Zeit darstellt. Die Region Ostravsko war in der Vergangenheit ein Ziel der polnischen Einwanderung, aber besonders Ostrau war ein multikultureller Ort, an dem die polnische, tschechische, deutsche und jüdische Bevölkerung nebeneinander lebte. Vor allem diese Besonderheiten bilden eine interessante Grundlage für die vorliegende Untersuchung.

Schlüsselwörter: Polen; Bild; Heterobild; Imago; Ethnotyp

\section{| Abstract}

\section{LUKÁš PĚCHULA}

Constructing Polish Heteroimage in the Interwar Novels of the Wider Ostrava Region: A Comparative Czech-German Study

This analysis aims to examine the construction of the Polish heteroimages in novels written between two World wars in the broader region Ostravsko. It is a comparative study which reflects Polish ethnotypes in a wide range of Czech and German authors. Broader Moravian-Silesian region was the target of Polish immigration, but especially Ostrava was also a multicultural center where Polish, Czech, German and Jewish People lived side by side. It is these specifics that create space for the interesting development of all ethnotypes which are the basis of this research.

Keywords: Pole; image; heteroimage; imago; ethnotype 


\section{| About the Author}

Mgr. Lukáš Pěchula, Ph.D. currently finished his studies for a Doctorate at the Department of Czech Literature and Literary Criticism, Faculty of Arts, University of Ostrava, Czech Republic. His main fields of interest are imagology and gender studies related to the interwar period of German and Czech literature.

E-mail: lukaspechula@seznam.cz 